

\title{
Mixed N-Aryl/Alkyl Substitution Favours an Unusual Tautomer of Near-Infrared Absorbing Azacalixphyrins
}

\author{
Lucien Lavaud, Cloé Azarias, Gabriel Canard, Simon Pascal, Denis
} Jacquemin, Olivier Siri

\section{- To cite this version:}

Lucien Lavaud, Cloé Azarias, Gabriel Canard, Simon Pascal, Denis Jacquemin, et al.. Mixed NAryl/Alkyl Substitution Favours an Unusual Tautomer of Near-Infrared Absorbing Azacalixphyrins. New Journal of Chemistry, 2020, 10.1039/D0NJ04587J . hal-02962328

\section{HAL Id: hal-02962328 \\ https://hal.science/hal-02962328}

Submitted on 15 Oct 2020

HAL is a multi-disciplinary open access archive for the deposit and dissemination of scientific research documents, whether they are published or not. The documents may come from teaching and research institutions in France or abroad, or from public or private research centers.
L'archive ouverte pluridisciplinaire HAL, est destinée au dépôt et à la diffusion de documents scientifiques de niveau recherche, publiés ou non, émanant des établissements d'enseignement et de recherche français ou étrangers, des laboratoires publics ou privés. 


\section{Mixed N-Aryl/Alkyl Substitution Favours an Unusual Tautomer of Near-Infrared Absorbing Azacalixphyrins}

Lucien Lavaud, ${ }^{\text {a }}$ Cloé Azarias, ${ }^{\text {b,c }}$ Gabriel Canard, a Simon Pascal, ${ }^{*, a}$ Denis Jacquemin, ${ }^{*, b}$ Olivier Siri*,a

${ }^{a}$ Aix Marseille Univ, CNRS UMR 7325, CINAM, Campus de Luminy, case 913, 13288 Marseille cedex 09, France.

E-mail:pascal@cinam.univ-mrs.fr; olivier.siri@univ-amu.fr

${ }^{b}$ Université de Nantes, CNRS, CEISAM UMR 6230, 2, rue de la Houssinière, 44322 Nantes, France. E-mail:

Denis.Jacquemin@univ-nantes.fr

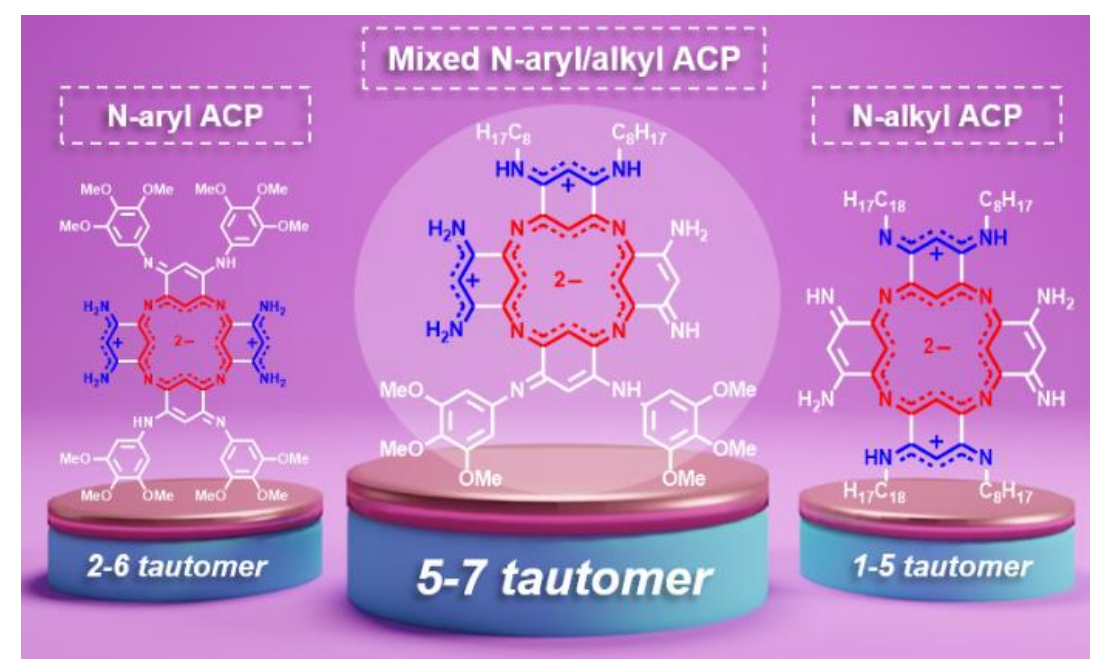

\section{ABSTRACT}

Azacalixphyrins are bis-zwitterionic aromatic macrocycles that feature absorption properties in the near-infrared range. Their $\mathrm{N}$-substitution is an efficient strategy for tuning the absorption maxima by stabilizing different tautomeric forms depending on the nature of the substituent (alkyl or aryl give 1-5 or 2-6 tautomers, respectively). This work depicts the synthesis of a new azacalixphyrin presenting both aryl and alkyl substituents. The joint experimental and theoretical study supports that the substitution pattern can be manipulated to counterbalance the repulsion of the two peripheral cationic charges to favour an unusual 5-7 tautomer. 


\section{Introduction}

The synthesis and investigation of near-infrared (NIR) organic absorbers is more than ever an area of interest due to the vast possibilities they offer for applications in many fields, e.g., organic electronics, photovoltaics, photodetection, and nonfluorescence based imaging techniques. ${ }^{1-9}$ While a large portion of the scientific literature reports the use of low band gap polymers or charged polymethine dyes, parallel efforts have been devoted to the development of aromatic macrocycles, and more specifically porphyrinoids, which are unique platforms for molecular engineering as they allow the fine tuning of the physico-chemical and optical properties, notably towards the NIR range. ${ }^{6,10-13}$ In this framework, the azacalixphyrin (ACP, Figure 1 ) is an unique NIR-absorbing macrocycle that features a di-anionic aromatic core and peripheral cationic trimethine units. ${ }^{14}$ This bis-zwitterion is constituted of four 2,5-diaminobenzoquinonediimine rings for which the peripheral trimethine units can be considered as independent from the core in the ground electronic state, according to the coupling principle of polymethine dyes. ${ }^{15-17}$ In 2013, ACP 1 was efficiently synthesized in no more than two synthetic steps (overall yield ca. $64 \%$ ) and presents an intense absorption at $c a .890 \mathrm{~nm}$. In silico investigations highlighted the high stability of ACPs and that their structure could undergo effective solvent-assisted tautomerism or be promptly protonated to generate polycationic species. ${ }^{14,18,19}$ Although initially poorly soluble in organic solvents, ACPs have been functionalized with $\mathrm{N}$-alkyl chains to improve their solubility which also led to supramolecular ribbon-like structures using $\mathbf{1 b b} .{ }^{20}$ Next, the $\mathrm{N}$ functionalization with aryl substituents, such as in 1aa, enabled to obtain bathochromic and hyperchromic shifts with absorption beyond $900 \mathrm{~nm}^{21}$ To date, ACPs have been identified as photoacoustic imaging probes upon NIR excitation, and the absorption of this family of dyes has been very recently extended to the second transparency window (NIR-II), i.e., beyond $1000 \mathrm{~nm}$ thanks to a fused ACP dimer. ${ }^{21,} 22$ Alongside these achievements, theoretical investigations allowed to predict NIR absorptions for metallated or C-substituted ACPs, ${ }^{23}$, 24 although such structures remain to be synthesized.
Globally, as ACPs constitute a new platform, their structureproperties relationships still need to be investigated to rationalize their optical behaviour, notably regarding the effect of the N-substituents on the distribution of the charges around the ACP core, which has a direct impact on the absorption maxima, by analogy with recently discovered zwitterionic 2,5 diamino-benzoquinonediimine and benzoquinonemonoimine moieties. ${ }^{25-27}$ Indeed, within ACPs, it has been theoretically and experimentally evidenced that the $\mathrm{N}$-substitution with alkyl or aryl functions promote the stabilization of different tautomeric structures with divergent absorption maxima. ${ }^{21,28}$ This marked difference is attributed to the preferred delocalization of the cationic charges between the $\mathrm{N}$-alkyl substituted trimethines in 1bb (favoured tautomer 1-5) while the delocalization extension brought by the nitrogen doublets on the $\mathrm{N}$-aryl moieties promotes the presence of the cationic charges within the unsubstituted trimethines in 1aa (favoured tautomer 2-6). ${ }^{28}$ We report here the first synthesis and characterizations of the dissymmetrical ACP 1a and the mixed N-aryl/alkyl ACP 1ab, for which the preferred tautomeric form 5-7 is evidenced by quantum chemical calculations and is correlated to the electrochemical and optical behaviours measured experimentally.

\section{Results and discussion}

\section{Synthesis}

The synthesis of the target $\mathrm{N}$-substituted ACPs 1a and 1ab was initiated from compound $2,{ }^{21}$ which undergoes two nucleophilic aromatic substitutions in presence of one equivalent of tetraaminobenzenes $\mathbf{3 a}$ or $\mathbf{3} \mathbf{b}$ to lead to the formation of azacalixarenes $\mathbf{4 a}$ or $\mathbf{4 a b}$, respectively (Scheme 1 ). This closing step is carried out at a concentration of $c a .6 \times 10^{-3} \mathrm{M}$ to favour an intramolecular second substitution and that the reaction proceeds from 0 to $80{ }^{\circ} \mathrm{C}$, providing the macrocycles with moderate to good yields after simple purification via precipitation in ethanol. The nitro functions of the azacalixarenes are reduced in presence of a catalytic amount of $\mathrm{Pd} / \mathrm{C}$ and with a large excess of hydrazine monohydrate.

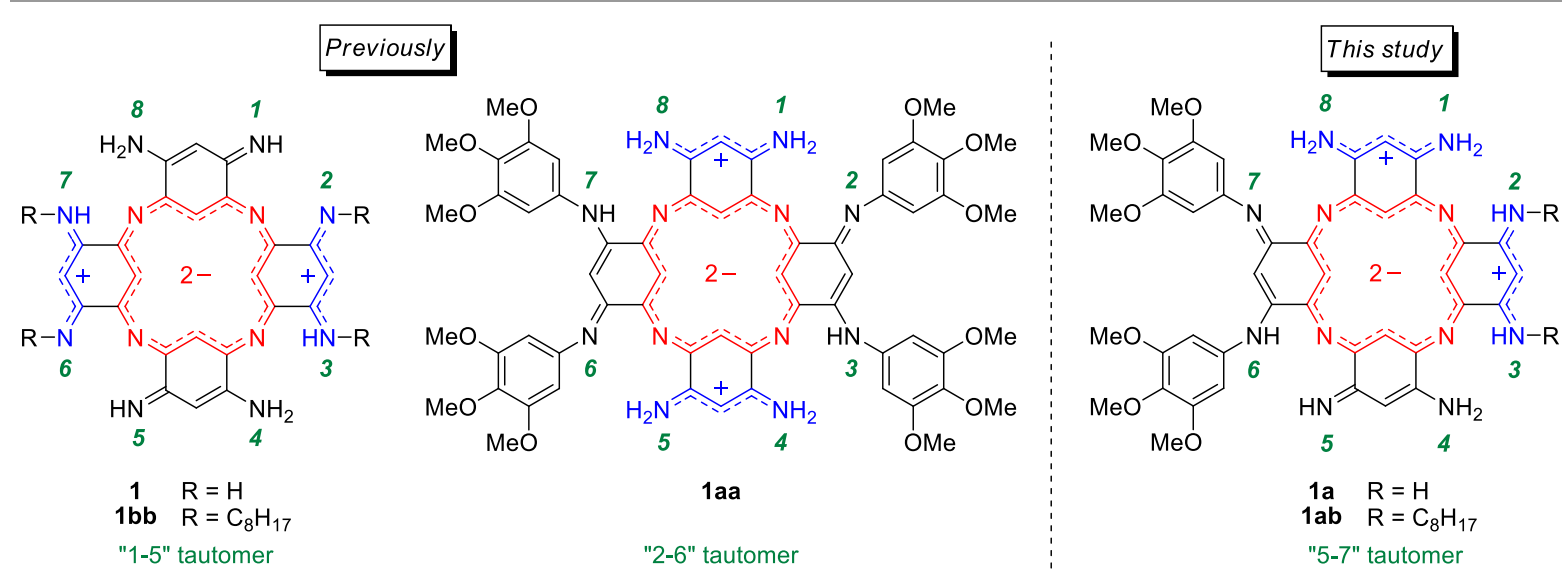

Figure 1. Scope of the previously synthesized and new azacalixphyrins (most stable tautomers). The two imine groups are at positions 1,5 for $\mathbf{1 b b}$ and 2,6 for $\mathbf{1 a a}$, hence the displayed structures correspond to the " $1-5$ " and " $2-6$ " tautomers, respectively. 
<smiles>COc1cc(Nc2cc(Nc3cc(OC)c(OC)c(OC)c3)c(Nc3cc(F)c([N+](=O)[O-])cc3[N+](=O)[O-])cc2Nc2cc([N+](=O)[O-])c(F)cc2[N+](=O)[O-])cc(OC)c1OC</smiles>

2

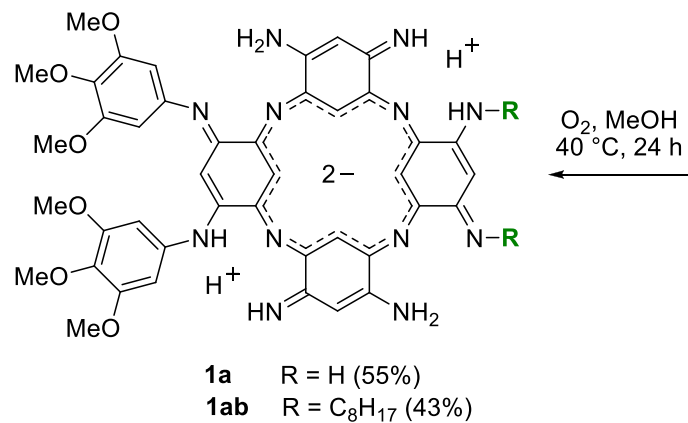

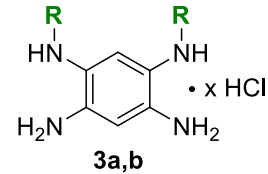

$$
\begin{gathered}
\begin{array}{c}
\text { DIPEA, MeCN, } \\
0^{\circ} \mathrm{C} \text { to reflux }
\end{array} \\
\mathrm{R}=\mathrm{H}, \mathrm{x}=4 \\
\mathrm{R}=\mathrm{C}_{8} \mathrm{H}_{17,} \mathrm{x}=2
\end{gathered}
$$

$\mathrm{NH}_{2} \mathrm{NH}_{2} \cdot \mathrm{H}_{2} \mathrm{O}$

$\mathrm{Pd} / \mathrm{C}$

THF, $\Delta$

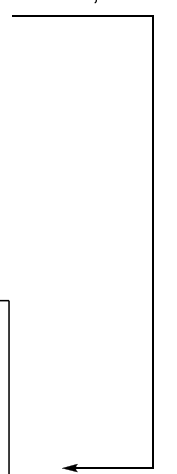<smiles>[R]Nc1cc(N[R])c(Nc2cc(Nc3cc(Nc4cc(Nc5cc(OC)c(OC)c(OC)c5)c(N)cc4N)c(Nc4cc(OC)c(OC)c(OC)c4)cc3N)c(N)cc2N)cc1I</smiles>

Scheme 1 . Synthesis of azacalixphyrins $1 \mathbf{a}$ and $\mathbf{1 a b}$

The macrocyclic octa-amino azacalixarene intermediates are then directly oxidized in presence of bubbling air in methanol solution at $40{ }^{\circ} \mathrm{C}$ to afford the corresponding ACPs $1 \mathbf{a}$ and $\mathbf{1 a b}$ in $55 \%$ and $43 \%$ yields, respectively, following purification via flash column chromatography on activated alumina. The structure of the products, both isolated as dark black-green solids, were confirmed by NMR spectroscopy and high resolution mass spectrometry which shows the expected ionization peaks $[\mathrm{M}+\mathrm{H}]^{+}$at $\mathrm{m} / z$ 811.3421 Da for 1 a and 1035.5938 Da for 1ab.

\section{Electrochemical properties}

The electrochemical properties of the ACPs presented in Figure 2 (see also Table S1 in the ESI) highlight the effect of the $\mathrm{N}$ substitution on their redox behaviour. As a reference, the tetraaryl-substituted ACP 1aa shows single electron reduction and oxidation waves at $-0.26 \mathrm{~V}$ and $0.54 \mathrm{vs}$. $\mathrm{Fc} / \mathrm{Fc}^{+}$, respectively. In contrast, di-aryl-substituted ACP 1a presents a reduction occurring at lower potential $(-0.39 \mathrm{~V})$ and a first oxidation wave is found at $0.49 \mathrm{~V}$. The substitution with alkyl chains in tetraoctylamino $\mathbf{1 b b}$ triggers a marked cathodic shift of the reduction wave by $240 \mathrm{mV}$, while the oxidation of the ACP is facilitated by $100 \mathrm{mV}$ compared to 1aa, these shifts being likely due to the higher electron-donating nature of the alkyl $\mathrm{N}$ substituents compared to the 3,4,5-trimethoxyphenyl moieties. Finally, the mixed alkyl-aryl compound 1ab shows a similar behaviour to that of dissymmetrical ACP 1a, with an irreversible reduction centred at $-0.34 \mathrm{~V}$ and an oxidation wave at $0.47 \mathrm{~V}$, this value being intermediate between those of $\mathbf{1} \mathbf{a a}$ and $\mathbf{1} \mathbf{b b}$.

\section{Photophysical properties}

The UV-vis-NIR absorption spectra of ACPs 1a and 1ab were recorded in DMSO solution, and in presence of 1,8diazabicyclo[5.4.0]undec-7-ene (DBU) or trifluoroacetic acid (TFA) to ensure the presence of neutral di-zwitterionic or diprotonated dicationic species, respectively (Figure 3 and Table 1). We underline that the solvatochromism of ACPs was also studied in DMF and methanol but no significant polarity effect could be detected as compared to DMSO (see Table S2 and Figure S15 in the ESI). ${ }^{\ddagger}$ In basic DMSO, the dissymmetrical ACPs $1 \mathrm{a}$ and $1 \mathrm{ab}$ exhibit absorption maxima at $820 \mathrm{~nm}$ and moderate

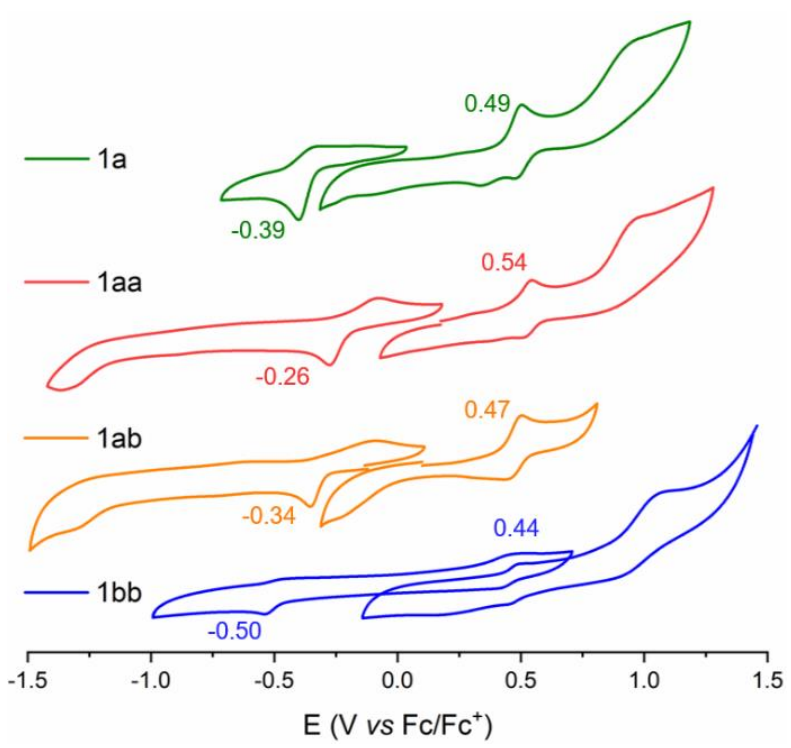

Figure 2. Cyclic voltammograms of ACPs in DMF solutions containing $0.1 \mathrm{M}$ of $\left[{ }^{n} \mathrm{Bu}_{4} \mathrm{NPF}_{6}\right]$. 

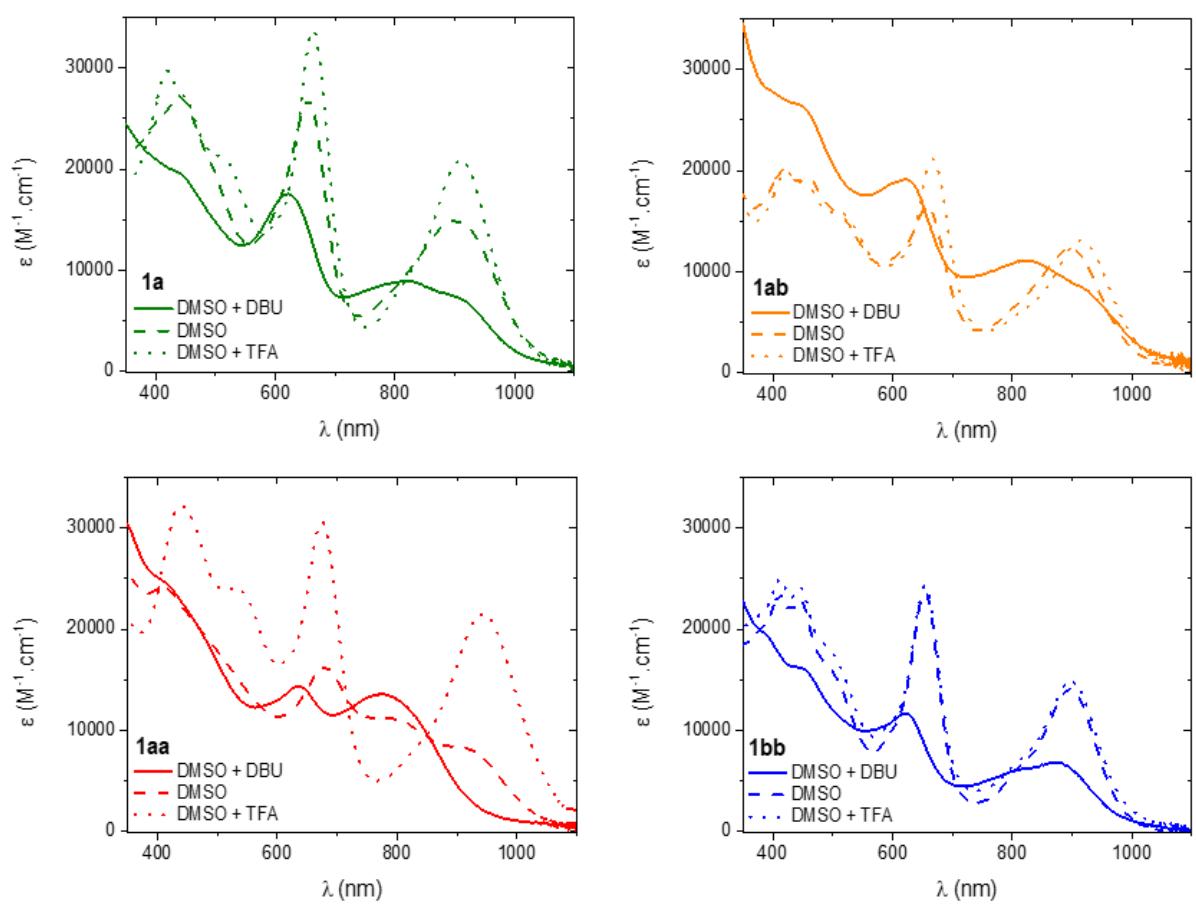

Figure 3. Absorption spectra of ACPs in basic (0.1 M DBU), neutral or acidic (0.1 M TFA) DMSO.

molar extinction coefficients $(\varepsilon)$ between $9000-11000 \mathrm{M}^{-1} \mathrm{~cm}^{-1}$. These values are intermediate compared to the reference tetraaryl derivative 1aa that presents the most blue-shifted absorption $\left(\lambda_{\max }=770 \mathrm{~nm}\right.$ ), while the tetra-alkyl analogue $\mathbf{1} \mathbf{b b}$ absorption maximum is found at $874 \mathrm{~nm}$. Worthy of note, this marked difference was attributed to the preferred tautomer 15 for $\mathbf{1 b b}$, while the most stable tautomer is 2-6 for $1 \mathbf{a a} .^{28}$ In DMSO, the absorption profiles are strongly red-shifted due to the protonation of the ACPs leading most probably to the (dominant) presence of di-cationic species. The four diprotonated ACPs present a maximum around $900 \mathrm{~nm}$, with higher $\varepsilon$ values $\left(12000-14000 \mathrm{M}^{-1} \mathrm{~cm}^{-1}\right)$, except for 1aa in DMSO that has $\varepsilon=8400 \mathrm{M}^{-1} \mathrm{~cm}^{-1}$ due the non-negligible presence of the neutral form 1aa in solution.

Table 1. Optical properties of ACPs in basic (0.1 M DBU), neutral or acidic (0.1 M TFA) DMSO.

\begin{tabular}{cccc} 
& DMSO $+0.1 \mathrm{M}$ & DMSO & $\begin{array}{c}\text { DMSO + 0.1 M } \\
\text { TFA }\end{array}$ \\
\cline { 2 - 4 } Dye & DBU & $\lambda_{\text {abs }}$ & \\
& $\lambda_{\text {abs }}(\mathrm{nm})$ & $(\mathrm{nm})$ & $\lambda_{\text {abs }}(\mathrm{nm})$ \\
& $\varepsilon\left(M^{-1} \mathrm{~cm}^{-1}\right)$ & $\varepsilon$ & $\varepsilon\left(\mathrm{M}^{-1} \mathrm{~cm}^{-1}\right)$ \\
& & $\left(\mathrm{M}^{-1} \mathrm{~cm}^{-1}\right)$ & \\
\hline \multirow{2}{*}{ 1a } & 819 & 900 & 910 \\
& 9000 & 14900 & 20900 \\
\hline \multirow{2}{*}{ 1aa } & 770 & 900 & 944 \\
& 13600 & 8400 & 21500 \\
\hline \multirow{2}{*}{ 1ab } & 820 & 898 & 915 \\
& 11100 & 12300 & 13100 \\
\hline \multirow{2}{*}{ 1bb } & 874 & 896 & 897 \\
& 6900 & 14200 & 14900 \\
\hline
\end{tabular}

In acidic DMSO, a slight red-shift is observed for $1 \mathbf{a}$ and $1 \mathbf{a b}\left(\lambda_{\max }\right.$ ca. $910-915 \mathrm{~nm}$ ), which is most presumably attributed to the presence of the di- and possibly tri-protonated forms in solution, as indicated by theoretical calculations (vide infra). Noteworthy, the poly-protonated forms of compound 1a and 1ab display the expected intermediate behaviour as compared

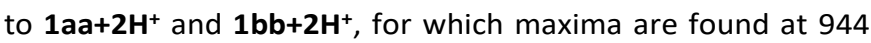
and $897 \mathrm{~nm}$, respectively. At this stage, the experimental electrochemical and photophysical measurements did not permit to elucidate the predominance of a given tautomer for 1a and $\mathbf{1 a b}$ in solution, and the compounds were therefore investigated in silico.

\section{Theoretical calculations}

To shed more light onto the experimental results, we have used $a b$ initio tools and more precisely DFT and TD-DFT. First, let us consider the doubly protonated forms for which only one tautomer is possible, as only amine groups are present. For $\mathbf{1 a}+\mathbf{2} \mathrm{H}^{+}$and $\mathbf{1 a b}+\mathbf{2} \mathrm{H}^{+}$, theory returns respective $\mathrm{NICS}(0)$ values of -7.8 and $-7.9 \mathrm{ppm}$ for the central macrocycle, clearly highlighting its strong aromatic character. For comparisons, the NICS(0) determined for $\mathbf{1}+\mathbf{2} \mathbf{H}^{+}, \mathbf{1} \mathbf{a a}+\mathbf{2} \mathbf{H}^{+}$and $\mathbf{1} \mathbf{b b}+\mathbf{2} \mathbf{H}^{+}$are similar: $-8.2,-7.5$ and $-8.0 \mathrm{ppm}$, respectively. ${ }^{28}$ Therefore, the new macrocycles show an aromaticity intermediate between their corresponding symmetric ones. The vertical absorption energy of the lowest excited-state computed at the TD-CAM-


with respect to $1 \mathbf{a a}+\mathbf{2} \mathbf{H}^{+}(912 \mathrm{~nm})$. This trend is alike the one found in the experiment. For $\mathbf{1} \mathbf{a b}+\mathbf{2} \mathbf{H}^{+}$, the theoretical value is $826 \mathrm{~nm}$, very close to the one of $\mathbf{1 a + 2 \mathbf { H } ^ { + }}$ which is consistent with the experimental values in DMSO. Eventually, for $\mathbf{1} \mathbf{b} \mathbf{b}+\mathbf{2} \mathbf{H}^{+}$, theory returns $891 \mathrm{~nm}$. The density difference plots for $\mathbf{1 a + 2 \mathbf { H } ^ { + }}$ and $\mathbf{1} \mathbf{a b}+\mathbf{2} \mathbf{H}^{+}$are displayed in Figure 4 . As can be seen, in the lowest excitation, the central dianionic ring act as a donor (mostly in yellow) whereas the external trimethine act as 



Figure 4. Density difference plots for $\mathbf{1} \mathbf{a}+\mathbf{2} \mathbf{H}^{+}$and $\mathbf{1} \mathbf{a b}+\mathbf{2} \mathbf{H}^{+}$. The yellow (burgundy) domains indicate decrease (increase) of electronic density upon excitation. A contour threshold of 0.0004 au is used.

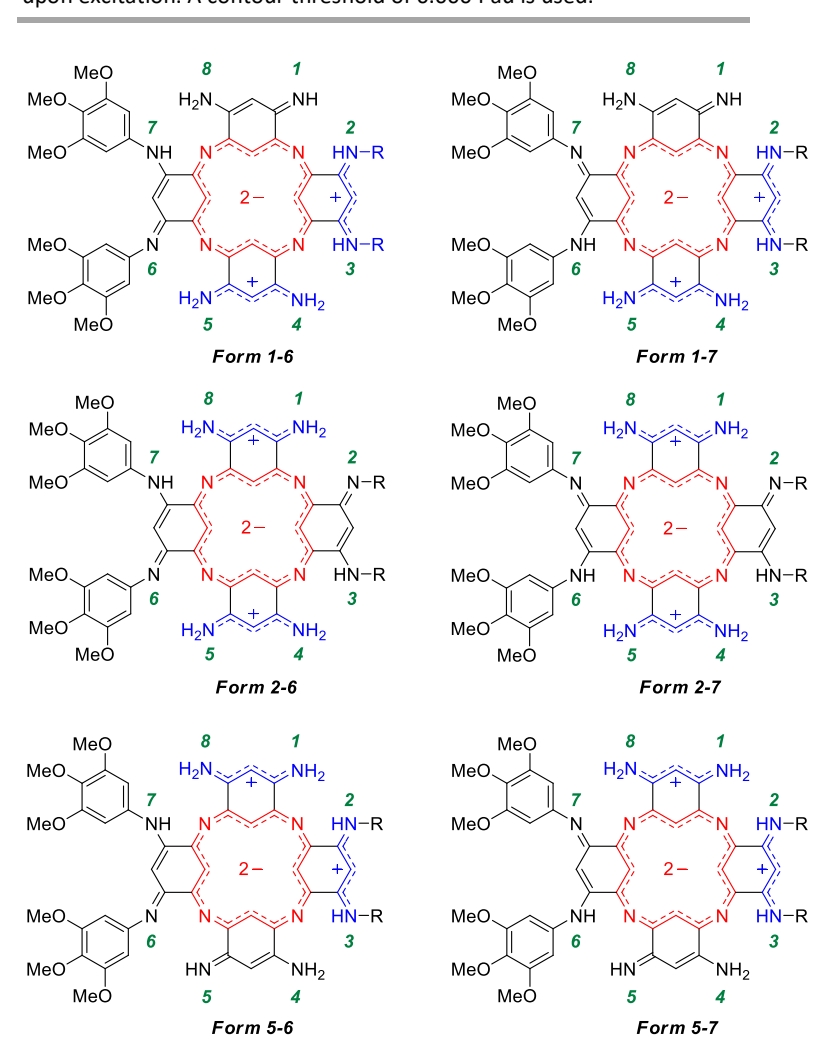

Figure 5. Selected most stable limit structures of azacalixphyrins 1 a $(R=$ $\mathrm{H})$ and $1 \mathrm{ab}\left(\mathrm{R}=\mathrm{C}_{8} \mathrm{H}_{17}\right)$. Tautomers denomination depends on the position of the two imine functions.

acceptors, a behaviour typical of ACPs. ${ }^{14,} 20,21,28$ There is however a clear dissymmetry in both compounds, the involvement of the trimethine bearing the aryl ring and the alkyl chains (for $\mathbf{1 a a}+\mathbf{2} \mathbf{H}^{+}$) being clearly larger than the ones of the unsubstituted trimethines. Let us now turn to the neutral forms of $\mathbf{1 a}$ and $\mathbf{1} \mathbf{a b}$. There is a mixture between two imine and six amine groups, and all possibilities have been considered (see Table 2, and Figures 5 and S16). As can be seen in Table 2, when the two imine functions are located on the same phenyl ring (1-8, 2-3, and 6-7), the structures are strongly disfavoured, as expected. For 1ab, putting imine groups on the alkyl-substituted nitrogen ( 2 and
3, see Figure 5) also yields relatively unstable tautomers. For $1 \mathbf{a}$, the most stable structures are 5$7,1-7,5-6,1-6,2-6$, and $2-7$ in increasing relative $G$ order, which is the tautomers bearing one imine on one aryl-substituted and one unsubstituted positions (see Figure 5). This is the first time in our modelling of ACP that such mixed tautomeric forms are favoured. ${ }^{28}$ As can be seen in Table 1, the four most stable tautomers show very alike $\mathrm{NICS}(0)$, close to -5 ppm indicating a strong aromatic character (yet less pronounced than in the diprotonated forms), as well as similar absorption positions (close to $800 \mathrm{~nm}$, i.e., slightly blue-shifted as compared to $\mathbf{1 a}+\mathbf{2} \mathbf{H}^{+}$). For 1ab, only four tautomers (5-7, 1-7, 5-6, and 1-6) have relative $G$ below $2 \mathrm{kcal}^{\mathrm{mol}}{ }^{-1}$, which are again those presenting mixed aryl/unsubstituted imines, the presence of alkyl chains strongly disfavouring 2-6 and 2-7. Again, these tautomers have rather alike aromaticities and absorption spectra, though the dispersion of the values seems higher in 1ab than in 1 a.

Eventually, to allow more straightforward comparisons between the experimental and theoretical absorption spectra, we provide in Figure 6 , the theoretical spectra of the various protonation states of $1 \mathbf{a}$ and $\mathbf{1 a b}$. These spectra are averages of all tautomeric forms presenting a $G<2 \mathrm{kcal}^{\mathrm{mol}} \mathrm{mor}^{-1}$ for each protonation states. For both dyes, theory foresees a slight batho- and hyperchromic shift in going from the doubly to the triply-protonated forms, the mono-protonated forms having intermediate absorption profiles between these two species. The absorption of the neutral species are blueshifted and significantly broader for the long wavelength band. All these trends are consistent with the experimental spectra displayed in Figure 3, and clearly indicate that in DMSO, there is already a substantial amount of protonated forms for both compounds, and that the addition of DBU is needed to obtain selectively neutral ACPs. 
Table 2. Relative free energy $(G), \operatorname{NICS}(0)$, and vertical absorption wavelengths $\left(\lambda_{S 1 \leftarrow s 0}\right)$ for the different tautomers of the ACPs 1a and 1ab. Tautomers equivalent by symmetry are not shown.

\begin{tabular}{|c|c|c|c|c|c|c|}
\hline \multirow{3}{*}{$\begin{array}{l}\text { I } \\
\text { mine } \\
\text { positi } \\
\text { on }\end{array}$} & \multicolumn{2}{|c|}{$\begin{array}{c}G \\
\left(\mathrm{kcal} \mathrm{mol}^{-}\right. \\
\left.{ }_{1}\right)\end{array}$} & \multicolumn{2}{|c|}{$\begin{array}{l}\mathrm{NIC} \\
\mathrm{S}(0) \\
(\mathrm{ppm})\end{array}$} & \multicolumn{2}{|c|}{$\begin{array}{l}\lambda_{\mathrm{s} 1<\mathrm{s0}} \\
(\mathrm{nm})\end{array}$} \\
\hline & 1 & 1 & 1 & & 1 & 1 \\
\hline & a & $a b$ & a & $1 \mathrm{ab}$ & a & $a b$ \\
\hline 1 & 4 & 8 & - & - & 8 & 8 \\
\hline-2 & .2 & .6 & 4.0 & 4.1 & 27 & 38 \\
\hline 1 & 4 & 9 & - & - & 8 & 8 \\
\hline-3 & .1 & .5 & 4.3 & 4.4 & 32 & 38 \\
\hline 1 & 5 & 5 & - & - & 8 & 8 \\
\hline-4 & .8 & .0 & 5.5 & 4.7 & 79 & 00 \\
\hline 1 & 4 & 4 & - & - & 9 & 9 \\
\hline-5 & .2 & .7 & 6.6 & 6.3 & 92 & 18 \\
\hline 1 & 0 & 1 & - & - & 8 & 8 \\
\hline-6 & .8 & .4 & 5.7 & 5.8 & 00 & 05 \\
\hline 1 & 0 & 0 & - & - & 8 & 7 \\
\hline-7 & .2 & .5 & 4.7 & 4.4 & 00 & 80 \\
\hline 1 & 1 & 1 & - & - & 9 & 8 \\
\hline-8 & 6.0 & 6.5 & 1.7 & 1.7 & 39 & 92 \\
\hline 2 & 1 & 2 & - & - & 8 & 8 \\
\hline-3 & 8.3 & 4.5 & 1.4 & 4.3 & 79 & 55 \\
\hline 2 & 3 & 7 & - & - & 8 & 8 \\
\hline-5 & .2 & .9 & 5.2 & 5.2 & 32 & 43 \\
\hline 2 & 1 & 5 & - & - & 9 & 9 \\
\hline-6 & .6 & .6 & 6.9 & 7.0 & 25 & 39 \\
\hline 2 & 1 & 5 & - & - & 8 & 8 \\
\hline-7 & .3 & .4 & 5.9 & 5.6 & 32 & 05 \\
\hline 2 & 2 & 6 & - & - & 8 & 8 \\
\hline-8 & .4 & .3 & 4.4 & 4.3 & 32 & 43 \\
\hline 5 & 0 & 0 & - & - & 7 & 7 \\
\hline-6 & .5 & .6 & 4.6 & 4.6 & 95 & 90 \\
\hline 5 & 0 & 0 & - & - & 8 & 8 \\
\hline-7 & .0 & .0 & 4.9 & 5.4 & 00 & 10 \\
\hline 5 & 5 & 5 & - & - & 9 & 1 \\
\hline-8 & .1 & .8 & 5.8 & 6.6 & 18 & 000 \\
\hline 6 & 9 & 1 & - & - & 8 & 8 \\
\hline-7 & .3 & 1.2 & 3.5 & 4.2 & 55 & 73 \\
\hline
\end{tabular}

\section{Conclusions}

Two new dissymmetrical ACP macrocycles were synthesized and presented in-between photophysical properties compared to the symmetrical $\mathrm{N}$-alkyl and $\mathrm{N}$-aryl substituted analogues. This study brought experimental and theoretical evidences that the mixed $\mathrm{N}$-substitution of the ACP using aryl and alkyl moieties was effective to force the establishment of an unusual 5-7 tautomer, with presence of the two cationic charges on the neighbour $\mathrm{N}$-alkyl and unsubstituted quinone units.
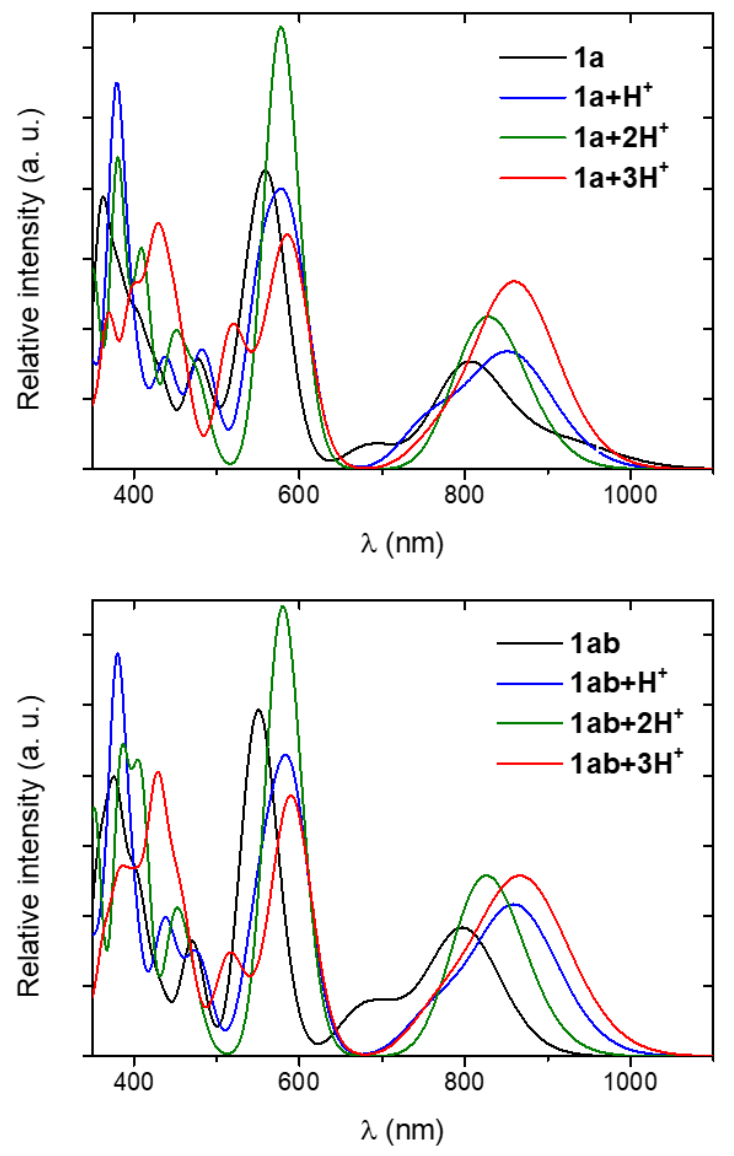

Figure 6. Theoretical absorption spectra of different protonation degrees of ACPs 1a (top) and 1ab (bottom) computed in DMSO. The spectra were obtained by convoluting the vertical TD-DFT spectrum with a Gaussian of $\mathrm{FWHM}=0.3 \mathrm{eV}$.

\section{Materials and methods}

Reagents, analytical methods and apparatus.

Compounds $\mathbf{2}$ and $\mathbf{3 b}$ were prepared following previously reported protocols. ${ }^{20,21}$ Melting points (M.P.) were measured in open capillary tubes with a STUART SMP30 melting points apparatus and are uncorrected. NMR spectra were recorded on a JEOL ECS400 NMR spectrometer at room temperature, otherwise noted. NMR chemical shifts are given in ppm ( $\delta$ ) relative to $\mathrm{Me}_{4} \mathrm{Si}$ with solvent resonances used as internal standards $\left(\mathrm{CD}_{3} \mathrm{OD}: 3.31 \mathrm{ppm}\right.$ for ${ }^{1} \mathrm{H}$ and 49.0 for ${ }^{13} \mathrm{C}\left[{ }^{1} \mathrm{H}\right]$; DMSO- $d_{6}: 2.50 \mathrm{ppm}$ for ${ }^{1} \mathrm{H}$ and 39.5 for $\left.{ }^{13} \mathrm{C}\left[{ }^{1} \mathrm{H}\right]\right)$. IR spectra were recorded on an Agilent Cary 630 FTIR equipped with an attenuated total reflectance (ATR) sampling. UV-Vis-NIR absorption spectra were recorded on a VARIAN CARY 50 SCAN spectrophotometer at room temperature using spectrophotochemical grade solvents, with concentrations of ACP $\mathrm{ca}$. $10^{-5} \mathrm{M}$. HRMS (ESI) and MS (ESI) analyses were performed on a QStar Elite (Applied Biosystems SCIEX) or a SYNAPT G2 HDMS (Waters) spectrometers by the "Spectropole" of the Aix-Marseille University. These two instruments are 
equipped with an ESI or MALDI source spectrometer, and a TOF mass analyser.

\section{Synthesis of bis(3,4,5-trimethoxyphenyl)- azacalix[4]arene (4a).}

To a solution of 2 ( $400 \mathrm{mg}, 0.477 \mathrm{mmol}, 1$ equiv.) in degassed MeCN (75 mL), was added commercial tetraaminobenzene tetrahydrochloride 3a (142 mg, $0.501 \mathrm{mmol}, 1.05$ equiv.) under argon atmosphere. Then degassed DIPEA ( $663 \mu \mathrm{L}, 3.816 \mathrm{mmol}, 8$ equiv.) was added dropwise at $0{ }^{\circ} \mathrm{C}$. The solution was stirred 3 hours at room temperature and finally heated to reflux overnight. After evaporation of the solvent, the resulting solid was washed with $\mathrm{EtOH}$ to afford the product as a brown powder (384 mg, 0.405 mmol, 85\%). M.P: > $300{ }^{\circ} \mathrm{C}$ (decomposition). ${ }^{1} \mathbf{H}$ NMR (400 MHz, DMSO- $\left.d_{6}\right): \delta=9.03(\mathrm{br} \mathrm{s}, 2 \mathrm{H}, \mathrm{NH}), 8.96(\mathrm{~s}$, $2 \mathrm{H}, \mathrm{ArH}), 8.89$ (s, 2H, NH), 7.41 (s, 2H, ArH), 6.87 (s, $1 \mathrm{H}, \mathrm{ArH}), 6.83(\mathrm{~s}, 2 \mathrm{H}, \mathrm{ArH}), 6.50(\mathrm{~s}, 1 \mathrm{H}, \mathrm{ArH}), 6.20$ (s, $4 \mathrm{H}, \mathrm{ArH}), 6.02(\mathrm{~s}, 1 \mathrm{H}, \mathrm{ArH}), 5.67(\mathrm{~s}, 2 \mathrm{H}, \mathrm{ArH}), 4.96(\mathrm{br}$ $\left.\mathrm{s}, 4 \mathrm{H}, \mathrm{NH}_{2}\right) .{ }^{13} \mathrm{C}$ NMR (100 MHz, DMSO-d $\left.\boldsymbol{d}_{6}\right): \delta=155.5$, $154.5,153.1,149.6,148.8,145.8,142.1,137.9$, $133.1,129.7,128.9,127.8,124.8,115.7,110.8$, 100.0, 99.6, 94.2, 60.1, 56.0. IR (neat, $\mathrm{cm}^{-1}$ ): $\mathrm{v}=3476$, 3390, 3338, 2936, 1612, 1565, 1507, 1403, 1321, $1275,1235,1197,1125,1101,1067,1041,1003,926$, 829, 882, 745, 692. HRMS (ESI-TOF): $m / z$ calculated for $\mathrm{C}_{42} \mathrm{H}_{41} \mathrm{~N}_{12} \mathrm{O}_{14} 4^{+}\left([\mathrm{M}+\mathrm{H}]^{+}\right) \quad 937.2860$, found 937.2858.

\section{Synthesis of bis(3,4,5-trimethoxyphenyl)-bis(octyl)- azacalix[4]arene (4ab).}

To a solution of 2 ( $150 \mathrm{mg}, 0,178 \mathrm{mmol}, 1$ equiv.) in degassed MeCN (30 mL), was added 3b (93 mg, 0.214 mmol, 1.2 equiv.) under argon atmosphere. Then degassed DIPEA ( $249 \mu \mathrm{L}, 1.42 \mathrm{mmol}, 8$ equiv.) was added dropwise at $0{ }^{\circ} \mathrm{C}$. The solution was stirred for 2 hours at $0{ }^{\circ} \mathrm{C}$, then for 1 hour at room temperature and finally heated to reflux for 2 hours. After evaporation of the solvent, the resulting solid was washed with EtOH to afford the product as a brown powder (114 mg, $0.098 \mathrm{mmol}, 55 \%)$. M.P: $273-275$ ${ }^{\circ} \mathrm{C} .{ }^{1} \mathrm{H}$ NMR (400 MHz, DMSO-d $\left.\boldsymbol{d}_{6}\right): \delta=9.04(\mathrm{~s}, 2 \mathrm{H}, \mathrm{NH})$, $8.99(\mathrm{~s}, 2 \mathrm{H}, \mathrm{ArH}), 8.92(\mathrm{~s}, 2 \mathrm{H}, \mathrm{NH}), 7.45$ (s, 2H, ArH), 7.31 (s, 1H, ArH), 6.81 (s, 1H, ArH), 6.55 (s, 1H, ArH), $6.27(\mathrm{~s}, 4 \mathrm{H}, \mathrm{ArH}), 5.73(\mathrm{~s}, 1 \mathrm{H}, \mathrm{ArH}), 5.55$ (s, 2H, ArH), $5.28(\mathrm{~s}, 2 \mathrm{H}, \mathrm{NH}), 3.60\left(\mathrm{~s}, 9 \mathrm{H}, \mathrm{OCH}_{3}\right), 3.58\left(\mathrm{~s}, 9 \mathrm{H}, \mathrm{OCH}_{3}\right)$, $2.87\left(\mathrm{~m}, 4 \mathrm{H}, \mathrm{CH}_{2}\right), 1.38\left(\mathrm{~m}, 4 \mathrm{H}, \mathrm{CH}_{2}\right), 1.29-1.04(\mathrm{~m}$, $\left.2 \mathrm{OH}, \mathrm{CH}_{2}\right), 0.82\left(\mathrm{t}, 3^{3} \mathrm{HH}_{\mathrm{H}}=6.5 \mathrm{~Hz}, 6 \mathrm{H}, \mathrm{CH}_{3}\right) .{ }^{13} \mathrm{C} \mathrm{NMR}$ (100 MHz, DMSO- $\boldsymbol{d}_{6}$ ): $\delta=153.0,149.7,149.1,145.8$, $141.7,137.7,133.0,130.4,129.2,127.7,125.0$, $124.9,115.3,109.9,99.2,94.4,91.6,60.1,55.8,42.8$, $31.3,30.7,28.9,28.8,28.6,26.7,22.1,13.9$. IR (neat, $\left.\mathbf{c m}^{-1}\right): v=3396,3336,2925,2852,2117,2087,1616$, $1565,1505,1462,1405,1322,1272,1238,1203$, 1126, 1065, 1006, 929, 881, 819, 744, 690. HRMS
(ESI-TOF): $m / z$ calculated for $\mathrm{C}_{58} \mathrm{H}_{73} \mathrm{~N}_{12} \mathrm{O}_{14}{ }^{+}\left([\mathrm{M}+\mathrm{H}]^{+}\right)$ 1161.5364 , found 1161.5367 .

\section{Synthesis $N^{2}, N^{4}$-bis(3,4,5-trimethoxylphenyl)- azacalixphyrin (1a).}

Compound 4a (100 mg, $107 \mu \mathrm{mol}, 1$ equiv.), Pd on carbon (5\% wt., $67 \mathrm{mg}, 32.1 \mu \mathrm{mol}, 0.3$ equiv.) and THF (30 mL) were introduced into a pressure bomb. Then hydrazine monohydrate $(551 \mu \mathrm{L}, 1.07 \mathrm{mmol}$, 100 equiv.) was added to the mixture before closing the bomb by a Teflon seal. The mixture was stirred at $80^{\circ} \mathrm{C}$ for 48 hours. The solution was then diluted with $\mathrm{MeOH}(120 \mathrm{~mL})$ before air was bubbled in the mixture at $40{ }^{\circ} \mathrm{C}$ for 24 hours. After evaporation of the solvent, the residue was purified on column chromatography (alumina 90 neutral, Merck ${ }^{\odot}$ grade I, DCM/MeOH $10 / 0$ to $8 / 2$ ) to afford the product as dark green solid (47.8 mg, $0.06 \mathrm{mmol}$, 55\%). M.P: > $300{ }^{\circ} \mathrm{C}$ (decomposition). ${ }^{\mathbf{1}} \mathbf{H}$ NMR (400 $\left.\mathbf{~ M H z}, \mathbf{C D}_{3} \mathrm{OD}\right)$ : $\delta=6.88(\mathrm{~s}, 1 \mathrm{H}, \mathrm{CH}), 6.81(\mathrm{~s}, 4 \mathrm{H}, \mathrm{ArH}), 6.39(\mathrm{~s}, 1 \mathrm{H}, \mathrm{CH})$, $6.31(\mathrm{~s}, 2 \mathrm{H}, \mathrm{CH}), 3.83-3.74\left(\mathrm{~m}, 18 \mathrm{H}, \mathrm{OCH}_{3}\right),-2.32(\mathrm{br}$ $\mathrm{s}, 4 \mathrm{H}, \mathrm{CH}$ ). IR (neat, $\mathrm{cm}^{-1}$ ): $\mathrm{v}=3091,2924,2112,2090$, $1999,1867,1593,1496,1453,1336,1300,1228$, 1166, 1117, 1033, 988, 813, 689. HRMS (ESI-TOF): $\mathrm{m} / \mathrm{z}$ calculated for $\mathrm{C}_{42} \mathrm{H}_{43} \mathrm{~N}_{12} \mathrm{O}_{6}{ }^{+}\left([\mathrm{M}+\mathrm{H}]^{+}\right)$811.3423, found 811.3421 .

\section{Synthesis of $N^{2}, N^{4}$-bis(3,4,5-trimethoxylphenyl)- $\mathbf{N}^{14}, \mathbf{N}^{16}$-bis(octyl)-azacalixphyrin (1ab).}

Compound 4ab (50 mg, $43 \mu \mathrm{mol}, 1$ equiv.), $\mathrm{Pd}$ on carbon ( $5 \%$ wt., $27 \mathrm{mg}, 13 \mu \mathrm{mol}, 0.3$ equiv.) and THF $(25 \mathrm{~mL})$ were introduced into a pressure bomb. Then hydrazine monohydrate $(209 \mu \mathrm{L}, 430 \mu \mathrm{mol}, 100$ equiv.) was added to the mixture before closing the bomb by a Teflon seal. The mixture was stirred at 120 ${ }^{\circ} \mathrm{C}$ for 24 hours. The solution was then diluted with $\mathrm{MeOH}(100 \mathrm{~mL})$ before air was bubbled in the mixture at $40{ }^{\circ} \mathrm{C}$ for 24 hours. After evaporation of the solvent, the residue was purified on column chromatography (alumina 90 neutral, Merck ${ }^{\odot}$ grade I, DCM/MeOH $10 / 0$ to $8 / 2$ ) to afford the product as dark green solid (19.4 mg, $19 \mu \mathrm{mol}, 43 \%)$. M.P: > 300 ${ }^{\circ} \mathrm{C}$ (decomposition). ${ }^{1} \mathbf{H}$ NMR (400 $\left.\mathbf{~ M H z}, \mathbf{C D}_{3} \mathrm{OD}\right): \delta=$ $6.82(\mathrm{~s}, 1 \mathrm{H}, \mathrm{CH}), 6.77$ (s, 4H, ArH), $6.33(\mathrm{~s}, 2 \mathrm{H}, \mathrm{CH})$, $5.99(\mathrm{~s}, 1 \mathrm{H}, \mathrm{CH}), 3.76\left(\mathrm{~s}, 6 \mathrm{H}, \mathrm{OCH}_{3}\right), 3.74(\mathrm{~s}, 12 \mathrm{H}$, $\left.\mathrm{OCH}_{3}\right), 1.88\left(\mathrm{~m}, 4 \mathrm{H}, \mathrm{CH}_{2}\right), 1.55-1.27\left(\mathrm{~m}, 24 \mathrm{H}, \mathrm{CH}_{2}\right)$, $0.84\left(\mathrm{t}, 6 \mathrm{H}, 3^{3} \mathrm{JH}=6.7 \mathrm{~Hz}, \mathrm{CH}_{3}\right),-1.43(\mathrm{br} \mathrm{s}, 1 \mathrm{H}, \mathrm{CH})$, 1.45 (br s, $1 \mathrm{H}, \mathrm{CH}$ ), -1.50 (br s, $2 \mathrm{H}, \mathrm{CH}$ ). No ${ }^{13} \mathrm{C}$ NMR spectrum could be recorded due to poorly resolved signals and poor solubility. IR (neat, $\mathbf{c m}^{-1}$ ): $v=3128$, 2919, 2849, 2344, 2113, 1922, 1588, 1500, 1449, 1339, 1301, 1229, 1173, 1120, 994, 814, 690. HRMS (ESI-TOF): $m / z$ calculated for $\mathrm{C}_{58} \mathrm{H}_{75} \mathrm{~N}_{12} \mathrm{O}_{6}{ }^{+}\left([\mathrm{M}+\mathrm{H}]^{+}\right)$ 1035.5927, found 1035.5938 . 


\section{Electrochemistry}

Cyclic voltammetry (CV) data were recorded using a BAS 100 (Bioanalytical Systems) potentiostat and the BAS100W software (v2.3). All the experiments were conducted under an argon atmosphere in a standard one-compartment using a three electrodes setup: a Pt working electrode $(\varnothing=1.6 \mathrm{~mm})$, a Pt counter electrode and an $\mathrm{Ag} / \mathrm{AgCl}$ reference electrode (filled with a $3 \mathrm{M} \mathrm{NaCl}$ solution). Tetra- $n$-butylammonium hexafluorophosphate ([TBA][PF 6 ) was used as supporting electrolyte $\left(10^{-1} \mathrm{M}\right)$, with a concentration of the electro-active compound ca. $10^{-3} \mathrm{M}$. The reference electrode was calibrated using ferrocene $\left(\mathrm{E}^{\circ}\left(\mathrm{Fc} / \mathrm{Fc}^{+}\right)=0.46 \mathrm{~V} / \mathrm{SCE}\right.$ in $\left.\mathrm{DMF}\right){ }^{29}$ The scan rate was $100 \mathrm{mV} / \mathrm{S}$. The solution was degassed using argon before recording each reductive scan, and the working electrode $(\mathrm{Pt})$ was polished before each scan recording.

\section{DFT and TD-DFT Calculations}

We have followed a methodology in line with the one used previously for ACPs. ${ }^{14,} 28$ More in details, we have used the Gaussian 16 code $^{30}$ to model the various charged species and tautomers using DFT and TD-DFT calculations. Geometry optimizations and frequency calculations were done at the PBEO/631G(d) level, ${ }^{31}$ considering solvent effects (here DMSO) using the continuum PCM model. ${ }^{32}$ During these calculations, we used tightened SCF $\left(10^{-10} \mathrm{au}\right)$ and geometry $\left(10^{-5} \mathrm{au}\right)$ convergence thresholds and selected the ultrafine DFT integration grid. We next performed single-point calculations at the same PCM-PBEO level with a larger basis set, i.e., 6$311+G(2 d, p)$, to obtain more accurate total energies. Indeed, the free energies of the various tautomers were obtained as $G=G^{6-31 G(d)}+E^{6-311+G(2 d, p)}-$ $E^{6-31 \mathrm{G}(\mathrm{d})}$. The aromaticity of the central macrocycle was estimated using the well-known NICS(0) model ${ }^{33}$ applying the gas $B 3 L Y P / 6-311++G(d, p)$ level, 34 which is standard for such calculations. The $\operatorname{NICS}(0)$ was selected rather than NICS(1) so as to ensure easy comparison with our previous works.18, 19, 22, 23 Finally, the vertical transition energies (20 lowest states) have been determined with the rangeseparated CAM-B3LYP functional ${ }^{35}$ and the same 6$311+G(2 d, p)$ basis set. During the TD-DFR calculations, the solvent (DMSO) effects were modelled using the non-equilibrium linear-response formulation of the PCM-TD scheme.

\section{Conflicts of interest}

There are no conflicts to declare.

\section{Acknowledgements}

All authors are indebted to the ANR (Agence Nationale de la Recherche) for support in the framework of the EMA grant. C.A. and D.J. warmly thank the CCIPL (Centre de Calcul Intensif des Pays de la Loire) for generous allocation of computational time.

\section{Notes and references}

¥ As previously noticed, ${ }^{21}$ the protic nature of methanol clearly influences the shape of the lowest energy transition, which is closest to the one of the diprotonated compounds for ACPs 1a and $1 \mathbf{a b}$, even in presence of DBU.

1. J. Fabian, H. Nakazumi and M. Matsuoka, Chem. Rev., 1992, 92, 1197-1226.

2. G. Qian and Z. Y. Wang, Chem. Asian J., 2010, 5, 1006-1029.

3. H. Dong, H. Zhu, Q. Meng, X. Gong and W. Hu, Chem. Soc. Rev., 2012, 41, 1754-1808.

4. K.-J. Baeg, M. Binda, D. Natali, M. Caironi and Y.-Y. Noh, Adv. Mater. 2013, 25, 42674295.

5. L. Dou, Y. Liu, Z. Hong, G. Li and Y. Yang, Chem. Rev., 2015, 115, 12633-12665.

6. P. Brogdon, H. Cheema and J. H. Delcamp, ChemSusChem, 2018, 11, 86-103.

7. H. Zhu, P. Cheng, P. Chen and K. Pu, Biomater. Sci., 2018, 6, 746-765.

8. X. Liu, Y. Lin, Y. Liao, J. Wu and Y. Zheng, J. Mater. Chem. C, 2018, 6, 3499-3513.

9. Z. Wu, Y. Zhai, H. Kim, J. D. Azoulay and T. N. Ng, Acc. Chem. Res., 2018, 51, 3144-3153.

$10 . \quad H$. Mori, T. Tanaka and A. Osuka, J. Mater. Chem. C, 2013, 1, 2500-2519.

11. T. Tanaka and A. Osuka, Chem. Soc. Rev., 2015, 44, 943-969.

12. T. D. Lash, Org. Biomol. Chem., 2015, 13, 7846-7878.

13. J. M. Merkes, L. Zhu, S. B. Bahukhandi, M. Rueping, F. Kiessling and S. Banala, Int. J. Mol. Sci., 2020, 21, 3082.

14. Z. Chen, M. Giorgi, D. Jacquemin, M. Elhabiri and O. Siri, Angew. Chem. Int. Ed., 2013, 52, 6250-6254.

15. S. Dähne and D. Leupold, Angew. Chem. Int. Ed., 1966, 5, 984-993.

16. O. Siri, P. Braunstein, M.-M. Rohmer, M. Bénard and R. Welter, J. Am. Chem. Soc., 2003, 125, 13793-13803.

17. S. Pascal and O. Siri, Coord. Chem. Rev., 2017, 350, 178-195.

18. G. Marchand, A. D. Laurent, Z. Chen, O. Siri and D. Jacquemin, J. Phys. Chem. A, 2014, 118, 8883-8888.

19. G. Marchand, P. Giraudeau, Z. Chen, M. Elhabiri, O. Siri and D. Jacquemin, Phys. Chem. Chem. Phys., 2016, 18, 9608-9615.

$20 . \quad$ Z. Chen, R. Haddoub, J. Mahé, G. Marchand, D. Jacquemin, J. Andeme Edzang, G. Canard, 
D. Ferry, O. Grauby, A. Ranguis and O. Siri, Chem. Eur. J., 2016, 22, 17820-17832.

21. L. Lavaud, S. Pascal, K. Metwally, D. Gasteau, A. Da Silva, Z. Chen, M. Elhabiri, G. Canard, D. Jacquemin and O. Siri, Chem. Commun., 2018, 54, 12365-12368.

22. L. Lavaud, C. Azarias, G. Canard, S. Pascal, J. Galiana, M. Giorgi, Z. Chen, D. Jacquemin and O. Siri, Chem. Commun., 2020, 56, 896899.

23. G. Marchand, O. Siri and D. Jacquemin, Phys. Chem. Chem. Phys., 2017, 19, 1590315913.

24. C. Azarias, S. Pascal, O. Siri and D. Jacquemin, Phys. Chem. Chem. Phys., 2018, 20, 20056-20069.

25. S. Pascal, L. Lavaud, C. Azarias, G. Canard, M. Giorgi, D. Jacquemin and O. Siri, Mater. Chem. Front., 2018, 2, 1618-1625.

26. S. Pascal, L. Lavaud, C. Azarias, A. Varlot, G. Canard, M. Giorgi, D. Jacquemin and O. Siri, J. Org. Chem., 2019, 84, 1387-1397.

27. A. T. Ruiz, M. H. E. Bousquet, S. Pascal, G. Canard, V. Mazan, M. Elhabiri, D. Jacquemin and O. Siri, Org. Lett., 2020, DOI: 10.1021/acs.orglett.0c02926.

28. G. Marchand, O. Siri and D. Jacquemin, Phys. Chem. Chem. Phys., 2016, 18, 2730827316.

29. N. G. Connelly and W. E. Geiger, Chem. Rev., 1996, 96, 877-910.

30. M. J. Frisch, et al. Gaussian 16, revision A.03, Wallignford, CT, USA, 2016.

31. C. Adamo and V. Barone, J. Chem. Phys., 1999, 110, 6158-6170.

32. J. Tomasi, B. Mennucci and R. Cammi, Chem. Rev., 2005, 105, 2999-3094.

33. Z. Chen, C. S. Wannere, C. Corminboeuf, R. Puchta and P. v. R. Schleyer, Chem. Rev., 2005, 105, 3842-3888.

34. A. D. Becke, J. Chem. Phys., 1993, 98, 56485652.

35. T. Yanai, D. P. Tew and N. C. Handy, Chem. Phys. Lett., 2004, 393, 51-57. 